\title{
There are Two Different Dysexecutive Syndromes
}

\author{
Alfredo Ardila* \\ Department of Communication Sciences and Disorders, Florida International University, Florida, USA
}

\begin{abstract}
The idea of "executive function" has become a fundamental concept in contemporary neurosciences. However, some disagreement remains around the question of unity or diversity (non-unitary) of executive functions and different points of view have been proposed. In this paper it is suggested that two major types of executive dysfunction syndromes can be separated: (a) Metacognitive executive dysfunction syndrome associated with dorsolateral frontal damage; and (b) Motivational/emotional executive dysfunction syndrome associated with orbitofrontal and medial frontal pathology. The first one is characterized by disturbances in intellectual abilities ("intelligence"), whereas the second one relates to impairments in behavioral control (disinhibition, impulsivity, etc.). Contemporary neuroimaging studies support this proposal.
\end{abstract}

Keywords: Dysexecutive syndromes; Prefrontal cortex; Executive functions

\section{Introduction}

The idea of "executive function" has become a fundamental concept in contemporary neurosciences [1]. The observation that the frontal lobes are involved in regulatory behaviors, including planning, self-monitoring, problem solving, inhibiting responses, strategy development and implementation, and working memory, resulted in the comprehensive term "executive function." Luria $[2,3]$ first suggested the idea of executive function. He distinguished three functional units in the brain: (a) arousal-motivation (limbic and reticular systems); (b) receiving, processing, and storing information (postrolandic cortical areas); and (c) programming, controlling, and verifying activity (frontal lobes) [2]. Luria mentions that this third unit has an executive role. Lezak [4] introduced the term as the dimension of human behavior that deals with "how" behavior is expressed. Initially, executive functions were conceptualized as having four components: The abilities of goal formation, planning, carrying out goal-directed plans, and effective performance. Repovs and Baddeley [5] grouped these behaviors into cognitive domains that included problems in planning, organizing behaviors, disinhibition, perseveration, reduced fluency, and initiation. Baddeley coined the term "dysexecutive syndrome."

Historically Phineas Gage became the most typical example for frontal lobe dysfunction, and the dysexecutive syndrome became synonymous with frontal lobe pathology [6]. Harlow [7] described Phineas Gage as a responsible foreman for a railroad company who suffered a tragic accident in which a tampering rod was projected through his frontal lobes when supervising construction on the railroad across Vermont. After the accident, he is described as "profane," "irascible," and "irresponsible." Interestingly, most of the disturbances reported in Phineas Gage refer to behavioral/emotional disturbances, or more exactly, disturbances in coordinating cognition and emotion/motivation. Harlow [8] described significant emotional and behavioral abnormalities in Phineas Gage but emphasized that no intellectual impairments were observed; he explicitly underlined that neither his memory nor his intelligence were compromised by the brain lesion. Harlow [7] stated that the "equilibrium or balances so to speak, between his intellectual faculties and animal propensities seem to have been destroyed. He is fitful, irreverent, indulging in gross profanity (which was not previously his custom), manifesting little or no deference for his fellows, and impatient of restraint or advice when it conflicts with his desires" (p. 389). Important to note, the frontal damage in Phineas Gage involved the orbital and medial aspects, but not the prefrontal dorsolateral area $[9,10]$.

The prefrontal lobe has extensive connections to subcortical and limbic system areas [11,12] and even its orbital portion could be regarded as an extension of the limbic system. The prefrontal cortex has also been identified as the core site for the integration of mood and cognition [13], and as a matter of fact, many of the disturbances observed in patients with prefrontal pathology (for instance, Phineas Gage) could be interpreted as disturbances in emotional control.

Currently, frontal lobe function research is utilizing functional brain imaging techniques to pinpoint the participation of different brain areas in executive function tasks [14]; thus, brain regions that contribute to dysexecutive syndromes may prove to be more multifunctional [15]. Functional imaging has demonstrated that adults and children with focal, especially frontal damage display similar executive function disturbances, such as attentional deficits, inability to inhibit a response, and impersistence of activity [16].

\section{One or Several Executive Functions?}

Some disagreement exists around the question of unity or diversity (non-unitary) of executive functions [17-21]. It is not easy to find a particular unitary factor saturating the different executive function tasks, and different proposals have been presented.

Behavior inhibition has been considered as the potentially single factor responsible for successful performance in different executive tests [22] alone or in combination with working memory [23]. Salthouse $[24,25]$ suggested that reasoning and perceptual speed could represent the underlying factors related to all executive functions. Salthouse [25] observed that performance on two common tests of executive functioning, the Wisconsin Card Sorting Test [26,27] and the Controlled Oral Word Association Test [28], were strongly correlated with reasoning ability and perceptual speed.

*Corresponding author: Alfredo Ardila, Department of Communication Sciences and Disorders, 11200 SW 8th Street, AHC3-431B, Florida International University, Miami, Florida 33199, USA, Tel: (305) 348-2750; E-mail: ardilaa@fiu.edu

Received February 11, 2013; Accepted April 16, 2013; Published April 18, 2013

Citation: Ardila A (2013) There are Two Different Dysexecutive Syndromes. J Neurol Disord 1: 114. doi:10.4172/2329-6895.1000114

Copyright: (c) 2013 Ardila A. This is an open-access article distributed under the terms of the Creative Commons Attribution License, which permits unrestricted use, distribution, and reproduction in any medium, provided the original author and source are credited. 
Other authors challenge the existence of such a unitary factor, suggesting the executive function includes a diversity of subcomponents. Godefroy et al. [29] emphasized that certain frontal lobe patients perform well on some tests purported to assess executive abilities but not on others. Factor analysis has also supported that executive functions include several subcomponents [30,31]. For example, Testa et al. [32] performed a factor analysis of 19 executive function tests administered to a nonclinical sample of 200 adults, and found 6 independent factors: prospective working memory, set-shifting and interference management, task analysis, response inhibition, strategy generation and regulation, and self-monitoring and set-maintenance. Noteworthy, correlations among different executive tests are frequently moderate or low, and many times lacking statistical significance [33-35], suggesting that they measure different underlying factors.

Some authors have preferred to take an intermediate position. Miyake et al. [36] studied three often-postulated aspects of executive functions (shifting, updating, and inhibition) and concluded that, although they are clearly distinguishable, they do share some underlying commonality. Based on the results of their study, the authors stated that executive functions are "separable but moderately correlated constructs" thus suggesting both unitary and nonunitary components of the executive system. By the same token, several authors have suggested different subcomponents of executive functions $[4,37-43]$

\section{Two Fundamental Dysexecutive Syndromes}

It seems evident that patients with prefrontal pathology can present intellectual abnormalities (problem solving difficulties, abstraction defects, etc.) and also emotional/ behavioral changes, as clearly illustrated in Phineas Gage classical case. Consequently, it may be conjectured that there are two different, but closely related types of executive functions [44-46] and two different dysexecutive syndromes; they probably appeared at different historical moments [47] and develop in children at different age [48].

The idea that there are two basic executive functions has been suggested by different authors; for instance, a distinction has been proposed between the "cool" cognitive aspects of executive functions, which are more associated with dorsolateral regions of the prefrontal cortex, and the "hot" affective aspects, which are more associated with the ventral and medial regions [49]. This hot/cool distinction has been applied to the development of executive functions in children [50]; it was observed that whereas cool (metacognitive) executive functions significantly correlated with general intellectual ability ("intelligence"), hot (emotional/motivational) executive functions are not related to general intellectual functioning (verbal mental age and performance mental age).

It could be argued that the use of the terms "cool" and "hot", however, could generate conflict, because behavioral symptoms could indeed be regarded as "cool" or "hot". As a matter of fact, the prefrontal behavioral symptoms could also divided into two syndromes: apathy, withdrawal, decreased communication, and depression as cingulate/ prefrontal medial syndrome (limbic symptoms-"cool"); and, on the other hand, impulsivity, disinhibition, personality disorders, aggressiveness, and other similar manifestations as orbitofrontal syndrome (symptoms paralimbic-"hot").

These two fundamental executive functions are:

(1) "Metacognitive executive functions" which include temporality of behavior, problem solving, abstracting, planning, anticipating the consequences of behavior, strategy development and implementation, and working memory (the usual understanding of executive functions, generally measured in neuropsychology executive functions tests); these are abilities mostly related with the dorsolateral area of the prefrontal cortex [51]. As a matter of fact, the dorsolateral prefrontal cortex has been observed to participate in planning, abstracting, problem solving, and working memory tasks. Using fMRI dorsolateral prefrontal activation has been found in tasks such as solving the Tower of Hanoi [52], Controlled Word Association Test (letter fluency) [53], working memory [54], and solving the Wisconsin Card Sorting Test [55].

(2) "Emotional/motivational executive functions," which are responsible for coordinating cognition and emotion. That means, the ability to fulfill basic impulses following socially acceptable strategies. Phineas Gage can be considered as the most typical example of a disturbance in emotional/ motivational executive functions. In this case, what is most important does not necessarily include what the best conceptual and intellectual result is, but what is in accordance with personal impulses [56]. In that regard, the core function of the prefrontal lobe is to find acceptable justifications for limbic impulses. Following socially acceptable strategies actually involves inhibition of selfish or unsociable basic impulses in the first place, but not necessarily arriving at the best conceptual solution. The ventromedial areas of the prefrontal cortex are involved in the expression and control of emotional and instinctual behaviors $[44,45]$. This function is related with so-called "inhibitory control" of behavior [57]. Clinical evidence $[2,51]$ as well as experimental research $[58,59]$ suggest that the neural substrate for this inhibitory function resides mainly in the medial and orbital portions of the prefrontal cortex. Fuster [45] points out that "The apparent physiological objective of inhibitory influences from orbitomedial cortex is the suppression of internal and external inputs that can interfere with whatever structure of behavior, speech, or cognition is about to be undertaken or currently underway" (page 382).

Noteworthy, research has shown that emotional executive functions (such as attention control) develop earlier in life (during the $1^{\text {st }}$ year), before the development of metacognitive executive functions (such as planning and verbal fluency), which develop around the age of 3 and are correlated with the development of a grammatical language [48].

\section{Metacognitive Executive Dysfunction: Dorsolateral Syndrome}

It has been suggested that the dorsolateral circuit is the most important to executive functioning [60]. The most frequently observed deficit is an inability to organize a behavioral response to novel or complex stimuli. Symptoms are on a continuum and reflect capacity to shift cognitive sets, engage existing strategies, and organize information to meet changing environmental demands.

Various researchers, including Luria [2], have noted perseveration, stimulus-bound behavior, echopraxia, and echolalia. Lateralization has been noted in executive dysfunction [61]. Ventral and dorsal portions of prefrontal cortex are believed to interact in the maintenance of rational and "non-risky" decision making [62]. According to Fuster $[45,63]$, the most general executive function of the lateral prefrontal cortex is the temporal organization of goal-directed actions. 


\section{Motivational/Emotional Executive Dysfunction: Orbitofrontal and Medial Frontal Syndrome}

Orbitofrontal damage has been associated with desinhibition, inappropriate behaviors, personality changes, irritability, mood liability, tactlessness, distractibility, and disregard of important events [51]. Patients with this syndrome are unable to respond to social cues. Noteworthy, it was observed by Laiacona et al. [64] that these patients have no difficulty with card sorting tasks. Eslinger and Damasio [65] coined the term "acquired sociopathy" to describe dysregulation that couples both a lack of insight and remorse regarding these behaviors.

The orbitofrontal cortex appears to be linked predominantly with limbic and basal forebrain sites. Medial frontal lobe damage causes apathy or abulia (a severe form of apathy). Acute bilateral lesions in the medial frontal area can cause akinetic mutism, in which the individual is awake and has self-awareness, but does not initiate behaviors [66]. According to Fuster $[45,63]$, the ventromedial areas of the prefrontal cortex are involved in expression and control of emotional and instinctual behaviors. Furthermore, the cingulated gyrus (medial frontal region) is closely related as well to the emotional/ motivational dysexecutive syndrome. Damage in the anterior cingulated gyrus causes apathy or abulia.

It seems evident that the dysexecutive (prefrontal) syndrome can have rather different clinical expressions (metacognitive and emotional/ motivational) depending upon the specific location of the damage.

There is solid evidence to assume that two different prefrontal systems support these two executive function subtypes. For instance, Gläscher et al. [67] used voxel based lesion symptom mapping (i.e., method and software for analyzing relationships between behavioral deficits in neurological populations and lesion sites associated with those deficits) in 344 individuals with focal brain lesions, including 165 involving prefrontal pathology; a comprehensive neuropsychological test battery was administered to all participants. It was demonstrated that there are two distinct functional-anatomical networks within the prefrontal cortex: (a) one associated with cognitive control (that is, "metacognitive executive functions," including response inhibition, conflict monitoring, and switching), and supported by the dorsolateral prefrontal cortex and anterior cingulate cortex; and (b) a second functional-anatomical network associated with value-based decision making ("emotional/motivational executive functions"), which included the orbitofrontal, ventromedial, and frontopolar cortex.

\section{Conclusion}

Regardless that the concept of executive function is relatively new in neurosciences, it has become a most important idea in understanding human behavior and cognition. There is not a general consensus yet if there is a single unitary factor underlying executive functions; or rather, "executive function" includes a diversity of subcomponents, and indeed there are diverse executive functions.

Two major anatomical systems have been demonstrated in the frontal lobe: dorsolateral and orbito/medial, associated with rather different neuropsychological syndromes; the first one is characterized by disturbances in temporal organization of behavior, problem solving difficulties, abstracting and planning impairments, and working memory defects (metacognitive executive dysfunction syndrome); the second is characterized by defects in inhibitory control (emotional/ motivations executive dysfunction syndrome). The first one is associated with disturbances in intellectual abilities ("intelligence"), whereas the second one relates to impairments in behavioral control (disinhibition, impulsivity, etc.). A similar distinction has been proposed by different authors; for instance, it has been mention the distinction cold/hot executive functions [49] associated with two different frontal systems (dorsolateral and ventral/medial) and impaired in different ways in cases of focal frontal pathology.

This proposal of two dysexecutive syndromes may have significant clinical consequence from the assessment/testing point of view: some specific tests (e.g., impulsivity inhibition tests, such as the Stroop test) are assessing motivational/emotional executive dysfunction; whereas other tests (e.g., card sorting and planning tests) are evaluating metacognitive executive dysfunction. By the same token, manage/ intevention has to be different, targeting behavioral disorders in the first case, and cognitive impairments in the second one.

\section{References}

1. Jurado MB, Rosselli M (2007) The elusive nature of executive functions: a review of our current understanding. Neuropsychol Rev 17: 213-233.

2. AR Luria A (1969) Frontal lobe syndromes. In: PJ Vinken, GW Bruyn, editors Handbook of clinical neurology. Vol 2. Amsterdam: North Holland.

3. Luria AR (1980) Higher cortical functions in man. New York: Consultants Bureau.

4. Lezak MD (1983) Neuropsychological assessment. (2ndedn) Oxford University Press, New York.

5. Repovs G, Baddeley A (2006) The multi-component model of working memory: explorations in experimental cognitive psychology. Neuroscience 139: 5-21.

6. Ardila A, Surloff C (2012) Executive dysfunction. San Diego: Medlink Neurology.

7. Harlow JM (1848) Passage of an iron rod through the head. Boston Medical and Surgical Journal 39: 389-393.

8. Harlow JM (1868) Recovery from the passage of an iron bar through the head. Publications of the Massachusetts Medical Society 2: 327-347.

9. Damasio H, Grabowski T, Frank R, Galaburda AM, Damasio AR (1994) The return of Phineas Gage: clues about the brain from the skull of a famous patient. Science 264: 1102-1105.

10. Ratiu P, Talos IF, Haker S, Lieberman D, Everett P (2004) The tale of Phineas Gage, digitally remastered. J Neurotrauma 21: 637-643.

11. H Barbas (2006) Organization of the principal pathways of prefronta lateral, medial, and orbitofrontal cortices primates and implications for their collaborative interaction in executive functions. In J Risberg, J Grafman, editors, The frontal lobes. Development, function and pathology. Cambridge: Cambridge University Press.

12. Damasio A, Anderson SW (1993) The frontal lobes. In: Heilman KM, Valenstein E (eds.)., Clinical neuropsychology. (4thedn) New York: Oxford University Press.

13. Mitchell RL, Phillips LH (2007) The psychological, neurochemical and functional neuroanatomical mediators of the effects of positive and negative mood on executive functions. Neuropsychologia 45: 617-629.

14. Szameitat AJ, Schubert T, Müller K, Von Cramon DY (2002) Localization of executive functions in dual-task performance with fMRI. J Cogn Neurosci 14: 1184-1199.

15. Lloyd D (2000) Virtual lesions and the not-so-modular brain. J Int Neuropsychol Soc 6: 627-635.

16. Filley CM, Young DA, Reardon MS, Wilkening GN (1999) Frontal lobe lesions and executive dysfunction in children. Neuropsychiatry Neuropsychol Behav Neurol 12: 156-160.

17. de Frias CM, Dixon RA, Strauss E (2006) Structure of four executive functioning tests in healthy older adults. Neuropsychology 20: 206-214.

18. Duncan J, Emslie H, Williams P, Johnson R, Freer C (1996) Intelligence and 
the frontal lobe: the organization of goal-directed behavior. Cogn Psychol 30: 257-303.

19. Grafman J (2006) Human prefrontal cortex: Processes and representations. In J Risberg J Grafman, editors, The frontal lobes. Development, function and pathology. Cambridge: Cambridge University Press.

20. Kimberg D, D'Esposito M, Farah M (1997) Cognitive functions in the prefrontal cortex-Working memory and executive control. Curr Direct Psychol Sci 6: 185-192.

21. Parkin AJ, Java RI (1999) Deterioration of frontal lobe function in normal aging: influences of fluid intelligence versus perceptual speed. Neuropsychology 13: 539-545.

22. Barkley RA (1997) ADHD and the nature of self-control. New York: Guilford Press.

23. Pennington BF, Ozonoff S (1996) Executive functions and developmental psychopathology. J Child Psychol Psychiatry 37: 51-87.

24. Salthouse TA (1996) The processing-speed theory of adult age differences in cognition. Psychol Rev 103: 403-428.

25. Salthouse TA (2005) Relations between cognitive abilities and measures of executive functioning. Neuropsychology 19: 532-545.

26. Berg EA (1948) A simple objective technique for measuring flexibility in thinking. J Gen Psychol 39: 15-22.

27. R Heaton R (1981) Wisconsin card sorting test: Manual. Odessa: Psychological Assessment Resources, Inc.

28. Benton AL, Hamsher K, Sivan AB (1994) Multilingual aphasia examination (3rd edn) lowa City, IA: AJA Associates.

29. Godefroy O, Cabaret M, Petit-Chenal V, Pruvo JP, Rousseaux M (1999) Control functions of the frontal lobes. Modularity of the central-supervisory system? Cortex 35: 1-20.

30. Stout D, Chaminade T (2007) The evolutionary neuroscience of tool making Neuropsychologia 45: 1091-1100.

31. Mäntylä T, Carelli MG, Forman H (2007) Time monitoring and executive functioning in children and adults. J Exp Child Psychol 96: 1-19.

32. Testa R, Bennett P, Ponsford J (2012) Factor analysis of nineteen executive function tests in a healthy adult population. Arch Clin Neuropsychol 27: 213224.

33. Friedman NP, Miyake A, Corley RP, Young SE, Defries JC, et al. (2006) Not all executive functions are related to intelligence. Psychol Sci 17: 172-179.

34. Lehto J (1996) Are executive function tests dependent on working memory capacity? The Quarterly Journal of Experimental Psychology 49: 29-50.

35. Salthouse TA, Atkinson TM, Berish DE (2003) Executive functioning as a potential mediator of age-related cognitive decline in normal adults. J Exp Psychol Gen 132: 566-594.

36. Miyake A, Friedman NP, Emerson MJ, Witzki AH, Howerter A, et al. (2000) The unity and diversity of executive functions and their contributions to complex "Frontal Lobe" tasks: a latent variable analysis. Cogn Psychol 41 49-100.

37. Anderson VA, Anderson P, Northam E, Jacobs R, Catroppa C (2001) Development of executive functions through late childhood and adolescence in an Australian sample. Dev Neuropsychol 20: 385-406.

38. Delis D, Kaplan E, Kramer N (2001) Delis-Kaplan executive function system. Psychological Assessment Resources, Inc.

39. Denckla MB (1994) Measurement of executive function. In: Lyon GR, editor. Frames of reference for the assessment of learning disabilities: new views on measurement issues. Paul H Brooks, Baltimore, MD.

40. Elliott R (2003) Executive functions and their disorders. Br Med Bull 65: 4959

41. Hobson P, Leeds L (2001) Executive functioning in older people. Rev Clin Gerontol 11: 361-372

42. Lafleche G, Albert M (1995) Executive function deficits in mild Alzheimer's disease. Neuropsychology 9: 313-320.

43. Piguet O, Grayson DA, Broe GA, Tate RL, Bennett HP, et al. (2002) Normal aging and executive functions in "old-old" community dwellers: poor performance is not an inevitable outcome. Int Psychogeriatr 14: 139-159.

44. Fuster JM (2001) The prefrontal cortex--an update: time is of the essence. Neuron 30: 319-333.

45. Fuster JM (2002) Frontal lobe and cognitive development. J Neurocytol 31: 373-385.

46. Happaney K, Zelazo PD, Stuss DT (2004) Development of orbitofrontal function: current themes and future directions. Brain Cogn 55: 1-10.

47. Ardila A (2008) On the evolutionary origins of executive functions. Brain Cogn 68: 92-99.

48. Ardila A (2013) Development of Metacognitive and Emotional Executive Functions in Children. Applied Neuropsychology Child.

49. Zelazo PD, Muller U (2002) Executive function in typical and atypica development. In U Goswami, editor, Handbook of childhood cognitive development. Oxford, UK: Blackwell.

50. Hongwanishkul D, Happaney KR, Lee WS, Zelazo PD (2005) Assessment of hot and cool executive function in young children: age-related changes and individual differences. Dev Neuropsychol 28: 617-644.

51. Stuss DT, Knight RT (2002) Principles of frontal lobe function. Oxford: Oxford University Press.

52. Fincham JM, Carter CS, van Veen V, Stenger VA, Anderson JR (2002) Neural mechanisms of planning: a computational analysis using eventrelated fMRI. Proc Natl Acad Sci U S A 99: 3346-3351.

53. Baldo JV, Schwartz S, Wilkins D, Dronkers NF (2006) Role of frontal versus temporal cortex in verbal fluency as revealed by voxel-based lesion symptom mapping. J Int Neuropsychol Soc 12: 896-900.

54. Yoon JH, Hoffman JN, D'Esposito M (2007) Segregation of function in the lateral prefrontal cortex during visual object working memory. Brain Res 1184: $217-225$.

55. Lie CH, Specht K, Marshall JC, Fink GR (2006) Using fMRI to decompose the neural processes underlying the Wisconsin Card Sorting Test. Neuroimage 30: 1038-1049.

56. Bechara A, Martin EM (2004) Impaired decision making related to working memory deficits in individuals with substance addictions. Neuropsychology 18: $152-62$.

57. Miller P, Wang XJ (2006) Inhibitory control by an integral feedback signal in prefrontal cortex: a model of discrimination between sequential stimuli. Proc Natl Acad Sci U S A 103: 201-206.

58. Leung HC, Cai W (2007) Common and differential ventrolateral prefrontal activity during inhibition of hand and eye movements. J Neurosci 27: $9893-$ 9900.

59. Medalla M, Lera P, Feinberg M, Barbas H (2007) Specificity in inhibitory systems associated with prefrontal pathways to temporal cortex in primates. Cereb Cortex 17: i136-150.

60. Cummings JL (1993) Frontal-subcortical circuits and human behavior. Arch Neurol 50: 873-880.

61. Goldberg E (2001) The Executive Brain: Frontal Lobes and the Civilized Mind. New York: Oxford University Press.

62. Manes F, Sahakian B, Clark L, Rogers R, Antoun N, et al. (2002) Decisionmaking processes following damage to the prefrontal cortex. Brain 125: 624 639 .

63. Fuster JM (1997) The prefrontal cortex: Anatomy physiology, and neuropsychology of the frontal lobe. Philadelphia: Lippincott-Raven.

64. Laiacona M, Santis A De, Barbarotto R, Basso A, Spagnoli D, Capitani E (1989) Neuropsychological follow-up of patients operated for aneurysms of anterior communicating artery. Cortex 25: 261-273.

65. Eslinger PJ, Damasio AR (1985) Severe disturbance of higher cognition after bilateral frontal lobe ablation: patient EVR. Neurology 35: 1731-1741.

66. Ross ED, Stewart RM (1981) Akinetic mutism from hypothalamic damage: successful treatment with dopamine agonists. Neurology 31: 1435-1439.

67. Gläscher J, Adolphs R, Damasio H, Bechara A, Rudrauf D, et al. (2012) Lesion mapping of cognitive control and value-based decision making in the prefrontal cortex. Proc Natl Acad Sci U S A 109: 14681-14686. 